\title{
Dynamic Mechanical Properties and Constitutive Relation of an Aluminized Polymer Bonded Explosive at Low Temperatures
}

\author{
Yuliang Lin, Binbin Xu, Rong Chen, Jingui Qin, and Fangyun Lu \\ College of Science, National University of Defense Technology, Changsha, Hunan 410073, China \\ Correspondence should be addressed to Yuliang Lin; ansen_liang@163.com
}

Received 11 March 2014; Accepted 14 May 2014; Published 22 May 2014

Academic Editor: Anindya Ghoshal

Copyright (C) 2014 Yuliang Lin et al. This is an open access article distributed under the Creative Commons Attribution License, which permits unrestricted use, distribution, and reproduction in any medium, provided the original work is properly cited.

\begin{abstract}
Polymer bonded explosives (PBXs) are widely used as energetic fillings in various warheads, which maybe are utilized under extreme environments, such as low or high temperatures. In this paper, the dynamic response of an aluminized polymer bonded explosive was tested at a range of temperatures from $-55^{\circ} \mathrm{C}$ to $-2^{\circ} \mathrm{C}$ and a fixed loading strain rate $\left(\sim 700 \mathrm{~s}^{-1}\right)$ with the split Hopkinson pressure bar (SHPB). The PBX tested is aluminized, which contains $76 \mathrm{wt} \% \mathrm{RDX}, 20 \mathrm{wt} \%$ aluminum powder, and $4 \mathrm{wt} \%$ polymer binder, respectively. The results show that the effect of temperature on the strength of the PBX is obvious at the tested strain rates. Based on the experimental results and prophase studies, a constitutive model was obtained, in which the effect of temperature and strain rate were considered. The modeling curves fit well with the experimental results, not only at low temperature under $0^{\circ} \mathrm{C}$, but also at room temperature $\left(20^{\circ} \mathrm{C}\right)$. The model may be used to predict the dynamic performances of the PBXs in various environments.
\end{abstract}

\section{Introduction}

Due to low sensitivity and high detonation performance, the polymer bonded explosives (PBXs) are commonly used as energetic fillings in various weapon systems. In addition, the PBXs feature favorable mechanical and physical properties and can be easily shaped for different warheads. Since the operation circumstances of the weapon systems are complex, the industrial and military technology research institutions require the energetic materials to be workable under extreme environments, such as wide temperature ranges. However, PBXs' main components are explosive crystal and polymer binder. Due to the fact that the latter can be easily affected by change in temperature, the mechanical properties of PBXs are usually nonlinear and highly temperature dependent. Further research is needed to fully characterize the dynamic mechanical properties of PBX over a wide temperature range, and the constitutive model is required to be developed to predict the dynamic mechanical properties at different temperatures.

Some research works on dynamic mechanical properties of PBXs have been done [1-17]. The dynamic and static mechanical properties of PBXs were very different [5]. Furthermore, researchers have paid more attention to the effect of temperature on dynamic mechanical response of PBXs [6-16]. The stress-strain responses of PBX9501 and mock 9501 were tested under different temperatures and strain rates [6]. Gray III et al. used a specially designed SHPB setup to obtain the compression properties of PBX9501 and PBX9502 over a wide range of temperatures from -55 to $+50^{\circ} \mathrm{C}$. They found that the strength of PBX9502 was lower than PBX9501, but the effect of temperature and strain rates was not as obvious as that of PBX9501 [7, 8]. In addition, they compared the compression properties of Kel-F 800T (the binder in PBX 9502) under dynamic loading and quasistatic loading at room temperature [8]. The difference of the effect of temperature on mechanical properties of a few energetic materials at high strain rate loading was also discussed [9, 10]. Three explosive formulation binders were measured by Cady et al. as a function of strain rate and temperature [11]. The EDC37 (a type of energetic composition) was tested to obtain the compressive strength over a wide range of strain rates $\left(10^{-8} \sim 10^{3} \mathrm{~s}^{-1}\right)$ at a fixed temperature $(293 \pm 2 \mathrm{~K})$ and over a wide range of temperatures $(208$ to $333 \mathrm{~K}$ ) at a fixed strain rate $\left(10^{-3} \mathrm{~s}^{-1}\right)$ [12]. Li et al. tested the dynamic compression of three PBXs with three different temperatures at different loading strain rates. Their conclusion was that the compressive yield strength of the PBXs was negatively 


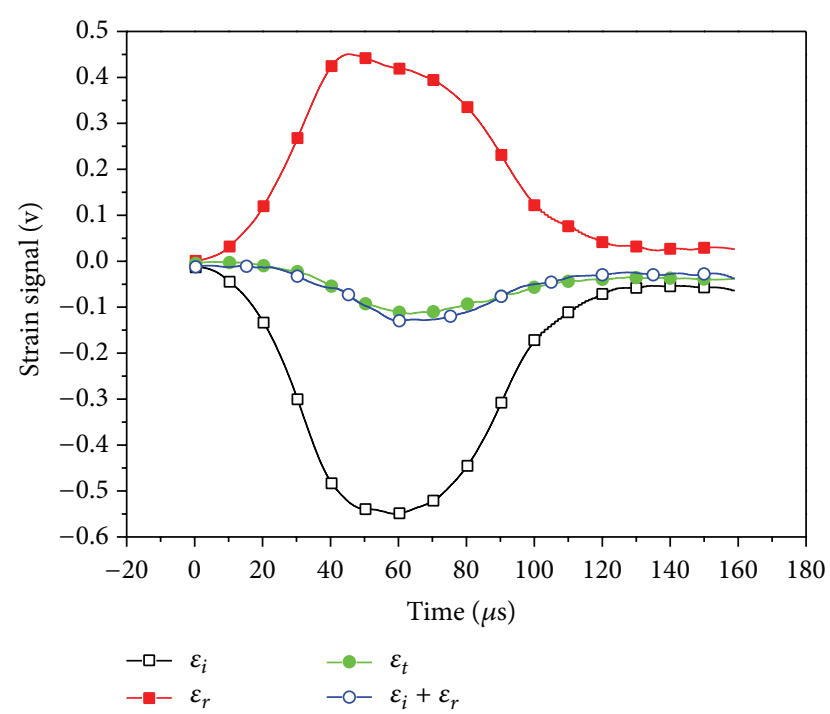

FIGURE 1: The strain signals in the bars. $\varepsilon_{i}$ : incident strain, $\varepsilon_{r}$ : reflected strain, and $\varepsilon_{t}$ : transmitted strain.

correlated with temperature and positively correlated with the strain rates $[13,14]$. By using the split Hopkinson pressure bar (SHPB), Qin et al. tested a PBX analog to investigate the effect of temperature and strain rate on mechanical properties [15]. Compressive and tensile properties of PBX 9501 and 9502 were tested at widely distinct temperatures and loading strain rates; the time-temperature analysis was made with the experimental stress-strain parameters [16]. However, studies of the constitutive relationship considering the effect of temperature are relatively few.

In this work, an aluminized polymer bonded explosive was tested by the split Hopkinson pressure bar at temperatures from $-2^{\circ} \mathrm{C}$ to $-55^{\circ} \mathrm{C}$. In order to more efficiently investigate the effect of temperature, the loading strain rates were fixed at around $700 \mathrm{~s}^{-1}$ with almost the same loadings. Based on the experimental results, previous work [17], and fundamental equations regarding polymer [18, 19], a constitutive equation was consequently derived, which can be used to quantify the effect not only of strain rate but also of temperature.

\section{Experimental Designs}

2.1. Material and Preparation. The material tested in this study is an aluminized polymer bonded explosive (PBX), which is composed of $76 \mathrm{wt} \% \mathrm{RDX}, 20 \mathrm{wt} \%$ aluminum powder, and $4 \mathrm{wt} \%$ binder. Finished samples were processed by compressing the energetic powder into cylinders $(15 \mathrm{~mm}$ in diameter, $8 \mathrm{~mm}$ in length) with a forming tool. In order to ensure evenness of the samples, the same powder and former were used through the compressing process. The density of the samples was controlled at $1.7 \mathrm{~g} / \mathrm{cm}^{3}$.

2.2. SHPB Testing. The SHPB at the laboratory of National University of Defense Technology was used to test the samples of aluminized PBXs. The material used for all bars is $7075 \mathrm{~A} \mathrm{Al}$ alloy, and the diameter of bars is $20 \mathrm{~mm}$. The lengths of incident bar, transmission bar, and striker bar are $2000 \mathrm{~mm}, 1200 \mathrm{~mm}$, and $200 \mathrm{~mm}$, respectively. In the experiment, the specimens were sandwiched between incident bar and transmission bar and were lubricated by molybdenum disulfide grease of a thin layer to reduce the effect of interfacial friction.

In order to achieve stress equilibrium in the specimens, which is the basic assumption of SHPB testing, the pulse shaping technology was used to change the profile of the incident waves [20]. The shapers were made of some soft materials and were placed on the impact end of incident bar. Due to the plastic deformation of the shaper, the rise time of the incident pulse may be lengthened, which would be sufficient to achieve stress equilibrium in the specimen. In this study, some $2.6 \mathrm{~mm} \times 2.6 \mathrm{~mm} \times 1.0 \mathrm{~mm}$ rubber cuboids were used as the shapers. The typical strain signals in the bars are shown in Figure 1, where the incident strain $\varepsilon_{i}$ and reflected strain $\varepsilon_{r}$ were measured by the strain gauges on the incident bar and the transmitted strain $\varepsilon_{t}$ was measured by the strain gauges on the transmission bar. During the experiments, same types of strain gauges as well as dynamic strain amplifiers with $1 \mathrm{MHz}$ bandwidth were utilized, and the data sampling frequency of oscilloscope was $10 \mathrm{MHz}$.

According to Figure 1, the sum of $\varepsilon_{i}$ and $\varepsilon_{r}$ is consistent with $\varepsilon_{r}$ during almost the entire loading process, which shows that the stress equilibrium is achieved in the experiment.

2.3. Low Temperature Control. In this work, the effect of temperature on dynamic properties of the aluminized PBX was planned to be studied at temperatures from $0^{\circ} \mathrm{C}$ to $-55^{\circ} \mathrm{C}$. In order to ensure a uniform temperature, the specimens were placed in a steel cylindrical vessel, which can be adequately cooled by helium gas. The temperature of specimen was monitored by a thermoelectric couple on its surface. This monitoring also helps to obtain the real-time temperature when the specimen was loaded on the bars. The temperature changes had also been recorded when the specimen was taken out of the cooling vessel until being loaded in a series of experiments. The records show that the temperature changes are within $2^{\circ} \mathrm{C}$, provided that only $2 \sim 3$ seconds are spent to take out the specimen from the vessel and then sandwich it between the two bars. These data facilitated for us to accurately propose the temperature of specimens in cooling vessel. The real-time temperature monitored by the thermoelectric couple on the surface of specimen was recorded as the temperature of each experiment. Small errors of temperature changes due to the thermoelectric couple and human recording were neglected, because the thermal conductivity of the PBX specimen was very small. In this study, the specimens were tested by SHPB at temperatures of $-2^{\circ} \mathrm{C},-11^{\circ} \mathrm{C},-21^{\circ} \mathrm{C},-29^{\circ} \mathrm{C},-35^{\circ} \mathrm{C},-40^{\circ} \mathrm{C},-48^{\circ} \mathrm{C}$, and $-55^{\circ} \mathrm{C}$.

2.4. Loading Strain Rate. To more efficiently investigate the effect of temperature, the uniaxial compression tests were controlled at a fixed strain rate $\left(\sim 700 \mathrm{~s}^{-1}\right)$ with the approximately same loading condition. The loading strain rates at different temperatures are listed in Table 1. 
TABLE 1: The loading strain rates at different temperatures.

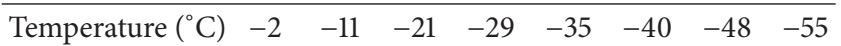

\begin{tabular}{lllllllll}
\hline Strain rate $\left(\mathrm{s}^{-1}\right)$ & 740 & 730 & 730 & 720 & 710 & 700 & 700 & 690
\end{tabular}

\section{Experimental Results}

The compressive stress-strain curves of the PBX at different temperatures are shown in Figure 2. From the figure, one can see that all the specimens failed. After reaching the peak, the stress decreases and the strain increases, which means that the deformation resistance of the specimen begins to decline. The peak stress is the failure strength of the specimen; the corresponding strain is called failure strain. As can be seen from Figure 2, the effect of temperature on mechanical parameters is evident. The failure strength is negatively correlated with temperature, and the strengthtemperature data can be linear fitting, as shown in Figure 3. In addition, the failure strain reduces from 0.035 to 0.025 when the temperature decreases from $-2^{\circ} \mathrm{C}$ to $-55^{\circ} \mathrm{C}$. This shows that PBX gains larger strength yet becomes more brittle as the temperature is lowered. The phenomenon is consistent with the general sense of polymer's properties at low temperatures. So, the polymer binder is likely to play an important role in the temperature effect of the PBX, though its proportion is little. However, the quantitative relation between the failure strain and temperature is not obvious, similar to that between the failure strength and temperature. Therefore, the relation between failure strain and temperature is not considered in this paper.

\section{Constitutive Model}

On the basis of prophase studies in the laboratory of National University of Defense Technology [17] and [18, 19], the constitutive model of the PBX at low temperature was discussed in this section.

The data shown in Figure 3 can be linear fitted as

$$
\sigma_{F}=84.73-0.253 T,
$$

where $\sigma_{F}$ is the failure strength ( $\left.\mathrm{MPa}\right)$ and $T$ is the temperature (Kelvin temperature, $\mathrm{K}, 0^{\circ} \mathrm{C}=273.15 \mathrm{~K}$ ). It should be noted that the data value is considered without dimensional analysis in (1).

The constitutive model of the PBX at room temperature had been studied in prophase work [17]. Consider the following:

$$
\begin{aligned}
\sigma=\sigma_{0} \cdot\left[\exp \left(\alpha\left(1-\frac{\rho}{\rho_{0}}\right)\right)+\beta\left(\frac{\dot{\varepsilon}}{\dot{\varepsilon}_{0}}-1\right)\right. \\
\left.+\gamma\left(1-\frac{\rho}{\rho_{0}}\right)\left(\frac{\dot{\varepsilon}}{\dot{\varepsilon}_{0}}-1\right)\right] \\
\cdot\left(A \varepsilon+B \varepsilon^{n}\right),
\end{aligned}
$$

where $\sigma$ is compression stress of the specimen $(\mathrm{MPa}), \rho_{0}$ is ideal density of the PBX (taken as $1.88 \mathrm{~g} / \mathrm{cm}^{3}$ in this study),

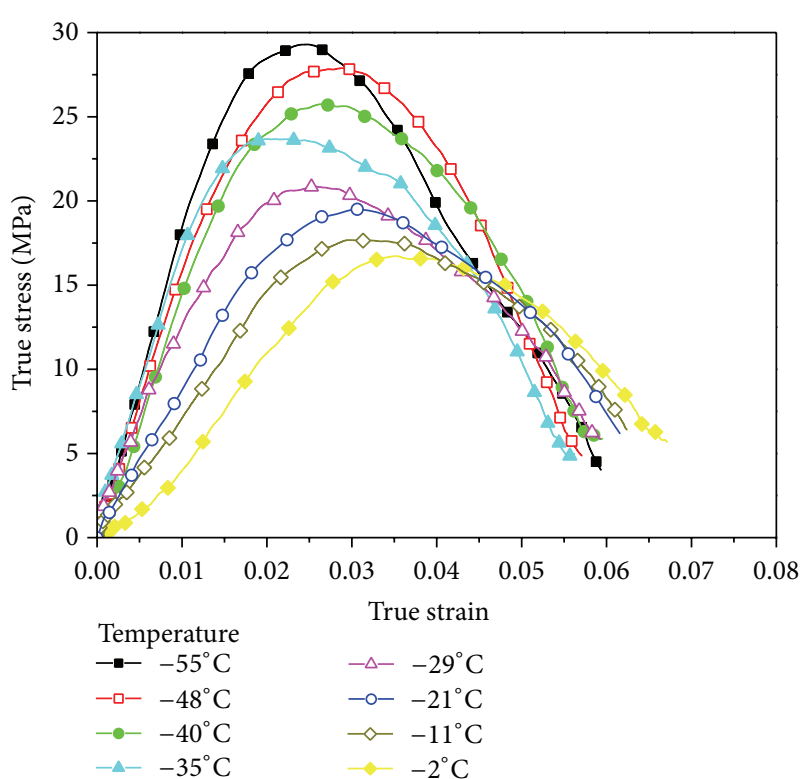

FIGURE 2: Stress-strain curves of the PBX at different temperatures.

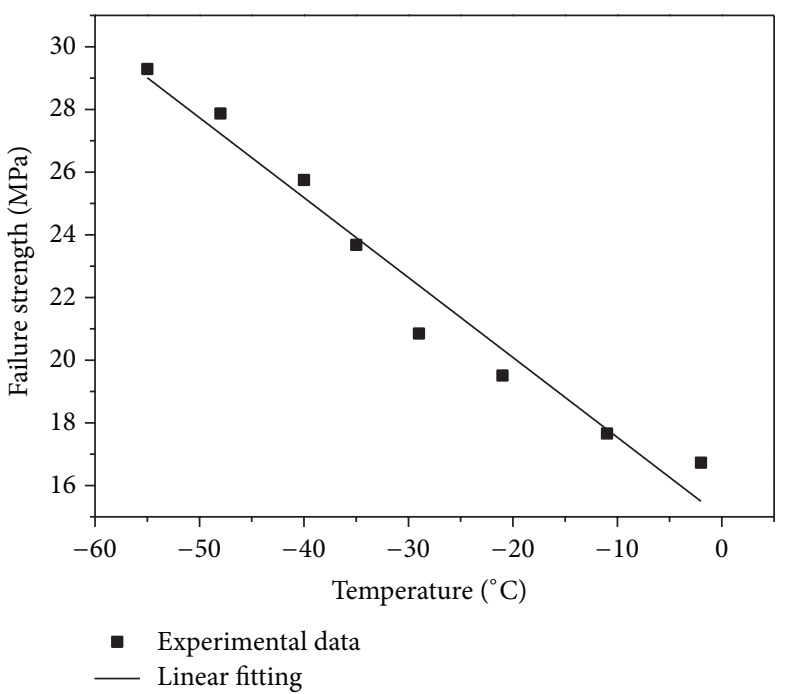

Figure 3: Failure strength versus temperature of the PBX.

$\rho$ is specimen's density $\left(1.70 \mathrm{~g} / \mathrm{cm}^{3}\right.$ in this study), $\dot{\varepsilon}_{0}$ is basic strain rate (taken as $\left.1 \mathrm{~s}^{-1}\right), \dot{\varepsilon}$ is loading strain rate $\left(\sim 700 \mathrm{~s}^{-1}\right.$ in this study), $\sigma_{0}$ is compression strength at the temperature of $0^{\circ} \mathrm{C}(273.15 \mathrm{~K})$ and with the strain rate of $1 \mathrm{~s}^{-1}(\mathrm{MPa}$, obtained by fitting experimental data), $\alpha$ is impact factor of density, $\beta$ is impact factor of strain rate, and $\gamma$ is cross-impact item. $\alpha, \beta$, and $\gamma$ are also obtained by fitting experimental data. Consider $\sigma_{0}=14.24 \mathrm{MPa}, \alpha=-17.04, \beta=0.0133$, and $\gamma=-0.0385$. $A, B$, and $n$ are essential parameters of the material regardless of the initial density, strain rates, and temperature, and all of them are obtained by fitting experimental data as well. Consider $A=130.8, B=-314.4$, and $n=1.325$ [17].

The relation between the failure strength and temperature is linear as shown in Figure 3 and (1). Furthermore, by 
TABLE 2: Parameters values of the constitutive model.

\begin{tabular}{lccccccccccc}
\hline Item & $\sigma_{0} / \mathrm{MPa}$ & $\rho_{0} /\left(\mathrm{g} / \mathrm{cm}^{3}\right)$ & $\dot{\varepsilon}_{0} / \mathrm{s}^{-1}$ & $\alpha$ & $\beta$ & $\gamma$ & $A$ & $B$ & $n$ & $C$ & $T_{0} / \mathrm{K}$ \\
\hline Value & 14.24 & 1.88 & 1 & -17.04 & 0.0133 & -0.0385 & 130.8 & -314.4 & 1.325 & 0.832 & 273.15 \\
\hline
\end{tabular}

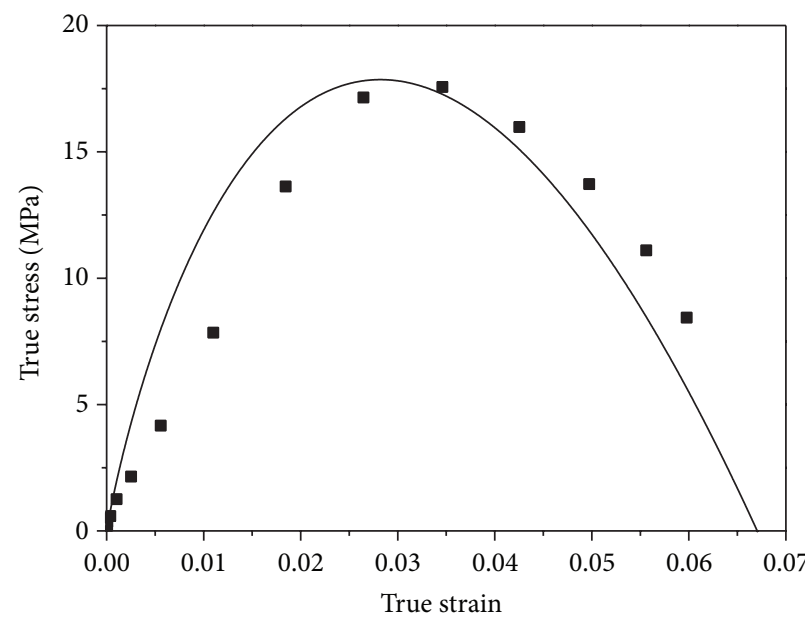

(a) $-11^{\circ} \mathrm{C}(262.15 \mathrm{~K})$

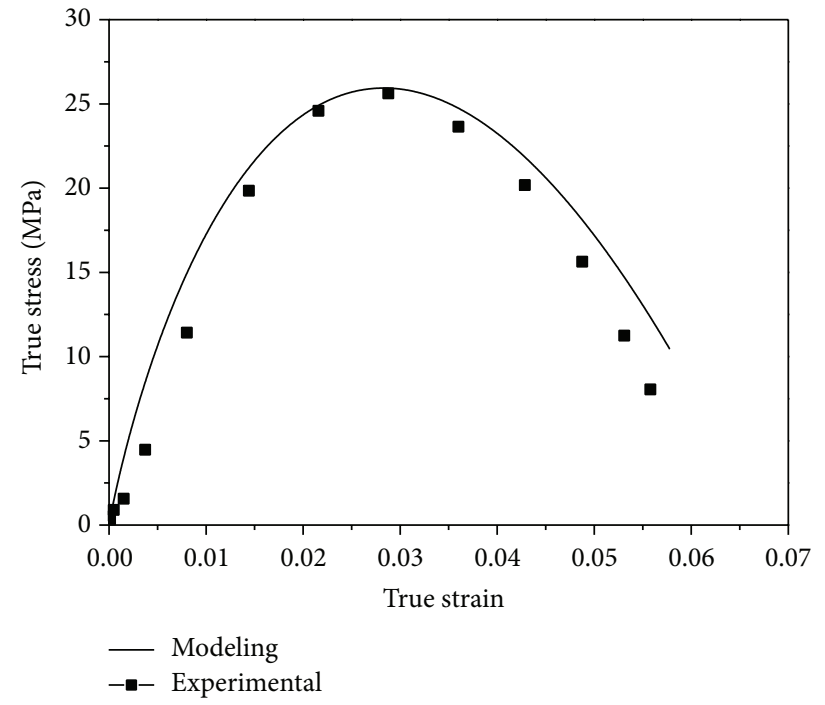

(c) $-40^{\circ} \mathrm{C}(233.15 \mathrm{~K})$

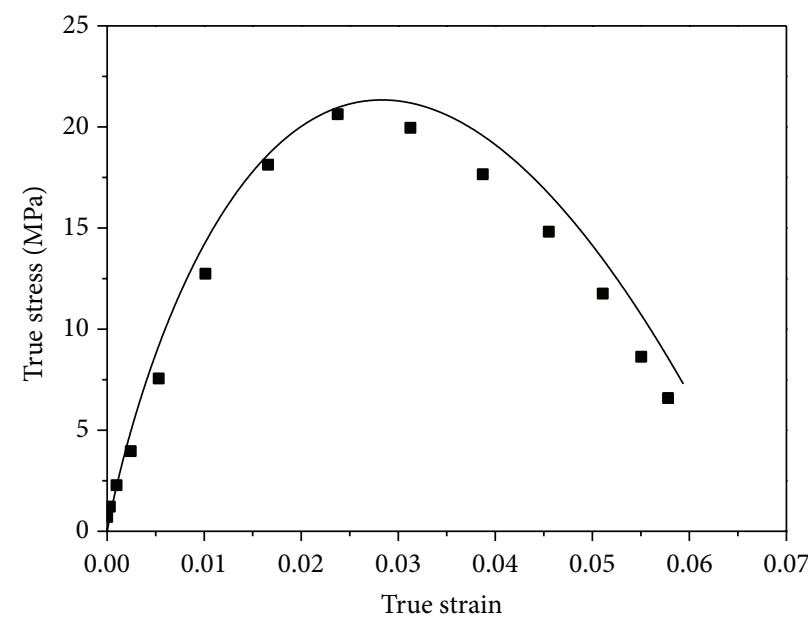

(b) $-29^{\circ} \mathrm{C}(244.15 \mathrm{~K})$

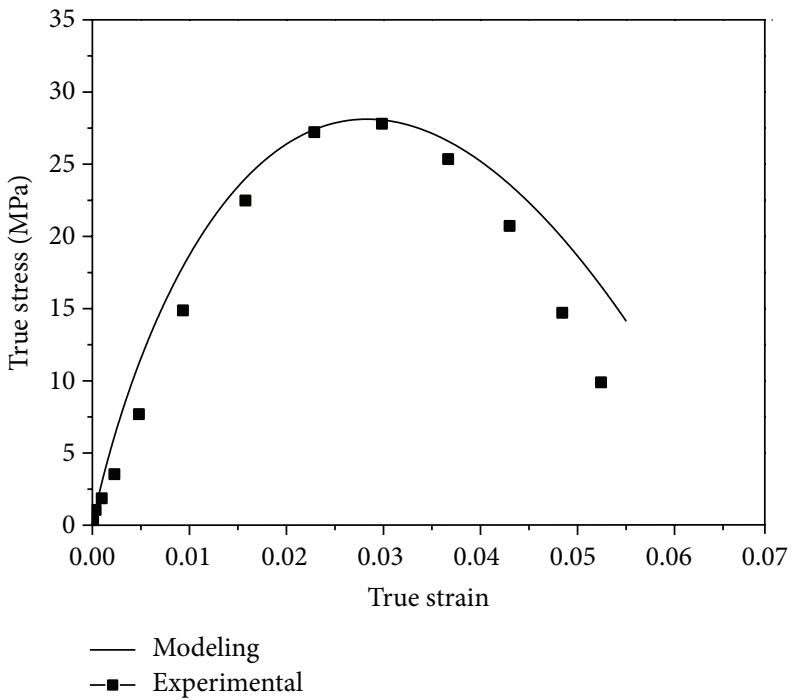

(d) $-48^{\circ} \mathrm{C}(225.15 \mathrm{~K})$

FIGURE 4: Comparison between model predictions and experimental results at different temperatures.

drawing lessons from the equation of Williams Lander Ferry (WLF) form [18] and considering the extensibility from low temperature (lower than $0^{\circ} \mathrm{C}$ ) to high temperature (higher than $0^{\circ} \mathrm{C}$ ), the equation of the effect of temperature can be introduced as

$$
f(T)=\left(1-C \frac{T}{T_{0}}\right)
$$

where $T$ is temperature of the specimen $(\mathrm{K}), T_{0}$ is reference temperature (taken as $273.15 \mathrm{~K}$ ), and $C$ is impact factor of temperature (obtained by fitting experimental data shown in Figure 3). Consider $C=0.832$. By combining (2) and (3), the complete constitutive model is generated as shown in (4), in which the effect of temperature and strain rates are both considered, and the parameters are listed in Table 2. Consider

$$
\begin{aligned}
\sigma=\sigma_{0} \cdot\left[\exp \left(\alpha\left(1-\frac{\rho}{\rho_{0}}\right)\right)+\beta\left(\frac{\dot{\varepsilon}}{\dot{\varepsilon}_{0}}-1\right)\right. \\
\left.+\gamma\left(1-\frac{\rho}{\rho_{0}}\right)\left(\frac{\dot{\varepsilon}}{\dot{\varepsilon}_{0}}-1\right)\right] \\
\cdot\left(A \varepsilon+B \varepsilon^{n}\right)\left(1-C \frac{T}{T_{0}}\right) .
\end{aligned}
$$

The comparison between the calculated results from models and experimental results at different temperatures is shown in Figure 4. The curves of model prediction are 


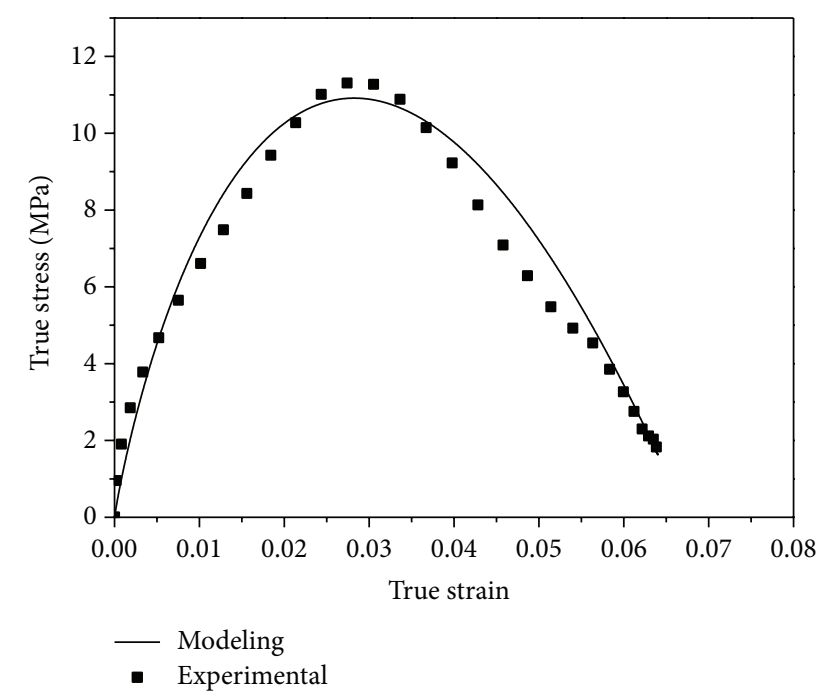

FIGURE 5: Comparison of model predictions and experimental results at $20^{\circ} \mathrm{C}$ (specimen's density is $1.7 \mathrm{~g} / \mathrm{cm}^{3}$, strain rate is $800 \mathrm{~s}^{-1}$ ).

well consistent with experimental results except for a few small details. Small deviations can be ignored in most engineering applications. In order to verify the applicability of the constitutive model at other temperatures above $0^{\circ} \mathrm{C}$, the result of the PBX (with the same density of $1.7 \mathrm{~g} / \mathrm{cm}^{3}$ ) at $20^{\circ} \mathrm{C}$ and under the strain rate of $\sim 800 \mathrm{~s}^{-1}$ was calculated using (4). The modeling curve is also well agreed with the experimental data reported earlier [17], as shown in Figure 5. These statistics indicate that the constitutive model is applicable for predicting the dynamic properties of the PBX at different temperatures. Further research is certainly needed to verify the applicability of the model at higher temperatures.

\section{Conclusion}

An aluminized polymer bonded explosive was tested by split Hopkinson pressure bar at low temperatures (from $-2^{\circ} \mathrm{C}$ to $-55^{\circ} \mathrm{C}$ ), and the stress strain curves were consequently obtained. Based on the experimental results and prophase studies, a constitutive model of the PBX was attained, in which the effect of temperature and strain rates are both considered. The following conclusions can therefore be drawn: (1) the tested PBX is temperature sensitive at low temperatures. This phenomenon is possibly because of the polymer binder which is the most temperature sensitive in the PBX compositions; (2) the failure strength of the PBX is negatively correlated with temperature and the PBX gains larger strength but becomes more brittle as the temperature is lowered; (3) the model predictions are well consistent with experimental results, when the specimens are at the temperature not only under $0^{\circ} \mathrm{C}$ but also above $0^{\circ} \mathrm{C}$.

\section{Conflict of Interests}

The authors declare that there is no conflict of interests regarding the publication of this paper.

\section{Acknowledgments}

This work was supported by the National Natural Science Foundation of China (Grant nos. 11172328 and 11132012). The authors would like to thank Ms. Kunyuan Zhang for proofreading the paper.

\section{References}

[1] K. G. Hoge, "The behavior of plastic bonded explosives under dynamic compressive loads," Applied Polymer Symposia, vol. 5, pp. 19-40, 1967.

[2] R. L. Peeters, "Characterization of plastic bonded explosives," Journal of Reinforced Plastics and Composites, vol. 1, no. 2, pp. 131-140, 1982.

[3] J. E. Field, S. J. Palmer P, and P. H. Pope, "Mechanical properties of PBX's and their behaviour during drop-weight impact," in Proceedings of the 8th International Detonation Symposium, Albuquerque, NM, USA, July 1985.

[4] S. J. Palmer, J. E. Field, and J. M. Huntley, "Deformation, strengths and strains to failure of polymer bonded explosives," Proceedings of the Royal Society A, vol. 440, pp. 399-419, 1993.

[5] D. R. Drodge, J. W. Addiss, D. M. Williamson, and W. G. Proud, "Hopkinson bar studies of a PBX simulation," Aip Conference Proceedings, vol. 955, no. 1, pp. 513-516, 2007.

[6] D. J. Funk, G. W. Laabs, P. D. Peterson, and B. W. Asay, "Measurement of the stress-strain response of energetic materials as a function of strain rate and temperature: PBX, 9501 and mock 9501," Aip Conference Proceedings, vol. 370, no. 1, pp. 145-148, 1996.

[7] G. T. Gray III, W. R. Blumenthal, D. J. Idar, and C. M. Cady, "Influence of temperature on the high-strain-rate mechanical behavior of PBX, 9501," Aip Conference Proceedings, vol. 429, no. 1, pp. 583-586, 1998.

[8] W. R. Blumenthal, G. T. Gray III, D. J. Idar et al., "Influence of temperature and strain rate on the mechanical behavior of $\mathrm{PBX}$, 9502 and Kel-F 800TM," Aip Conference Proceedings, vol. 505, no. 1, pp. 671-674, 2000.

[9] G. T. Gray III, D. J. Idar, W. R. Blumenthal, C. M. Cady, and P. D. Peterson, "High-and-low strain rate, compression of several energetic material composites as a function of strain rate and temperature," in Proceedings of the 11th International Detonation Symposium, Snowmass, Colo, USA, August-September 1998.

[10] R. K. Govier, G. T. Gray III, and W. R. Blumenthal, "Comparison of the influence of temperature on the high-strain-rate mechanical responses of PBX 9501 and EDC37," Metallurgical and Materials Transactions A: Physical Metallurgy and Materials Science, vol. 39, no. 3, pp. 535-538, 2008.

[11] C. M. Cady, W. R. Blumenthal, G. T. Gray III, and D. J. Idar, "Mechanical properties of plastic-bonded explosive binder materials as a function of strain-rate and temperature," Polymer Engineering and Science, vol. 46, no. 6, pp. 812-819, 2006.

[12] D. M. Williamson, C. R. Siviour, W. G. Proud et al., "Temperature-time response of a polymer bonded explosive in compression (EDC37)," Journal of Physics D: Applied Physics, vol. 41, no. 8, Article ID 085404, 10 pages, 2008.

[13] J. Li, F. Lu, J. Qin et al., "Effects of temperature and strain rate on the dynamic responses of three polymer-bonded explosives," The Journal of Strain Analysis for Engineering Design, vol. 47, no. 2, pp. 104-112, 2011. 
[14] J. Li, F. Lu, R. Chen et al., "Dynamic behavior of three PBXs with different temperatures," in Dynamic Behavior of Materials, Volume 1, Conference Proceedings of the Society for Experimental Mechanics (June 2011), Uncasville, Conn, USA, pp. 135-140, Springer, 2011.

[15] J. Qin, Y. Lin, F. Lu, Z. Zhou, R. Chen, and J. Li, "Dynamic compressive properties of a PBX analog as a function of temperature and strain rate," in Dynamic Behavior of Materials, Volume 1, Conference Proceedings of the Society for Experimental Mechanics (June 2011), Uncasville, Conn, USA, pp. 141-146, Springer, 2011.

[16] D. G. Thompson, R. Deluca, and G. W. Brown, "Timetemperature analysis, tension and compression in PBXs," Journal of Energetic Materials, vol. 30, no. 4, pp. 299-323, 2012.

[17] R. Chen, F. Lu, Y. Lin, and R. Wang, "Mechanical behavior and constitutive model of pressed aluminized explosive," Chinese Journal of Energetic Materials, vol. 15, no. 5, pp. 460-463, 2007.

[18] M. L. Williams, R. F. Landel, and J. D. Ferry, "The temperature dependence of relaxation mechanisms in amorphous polymers and other glass-forming liquids," Journal of the American Chemical Society, vol. 77, no. 14, pp. 3701-3707, 1955.

[19] D. Porter and P. J. Gould, "A general equation of state for polymeric materials," Journal de Physique IV, vol. 134, pp. 373378, 2006.

[20] D. J. Frew, M. J. Forrestal, and W. Chen, "Pulse shaping techniques for testing brittle materials with a split Hopkinson pressure bar," Experimental Mechanics, vol. 42, no. 1, pp. 93-106, 2002. 

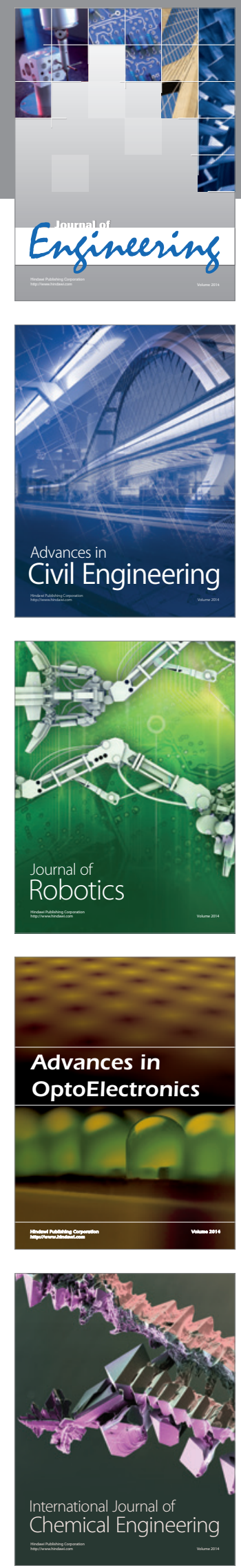

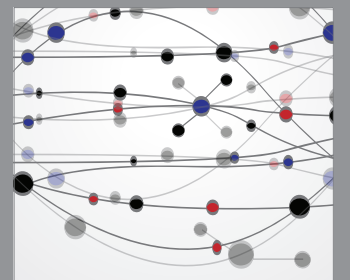

The Scientific World Journal
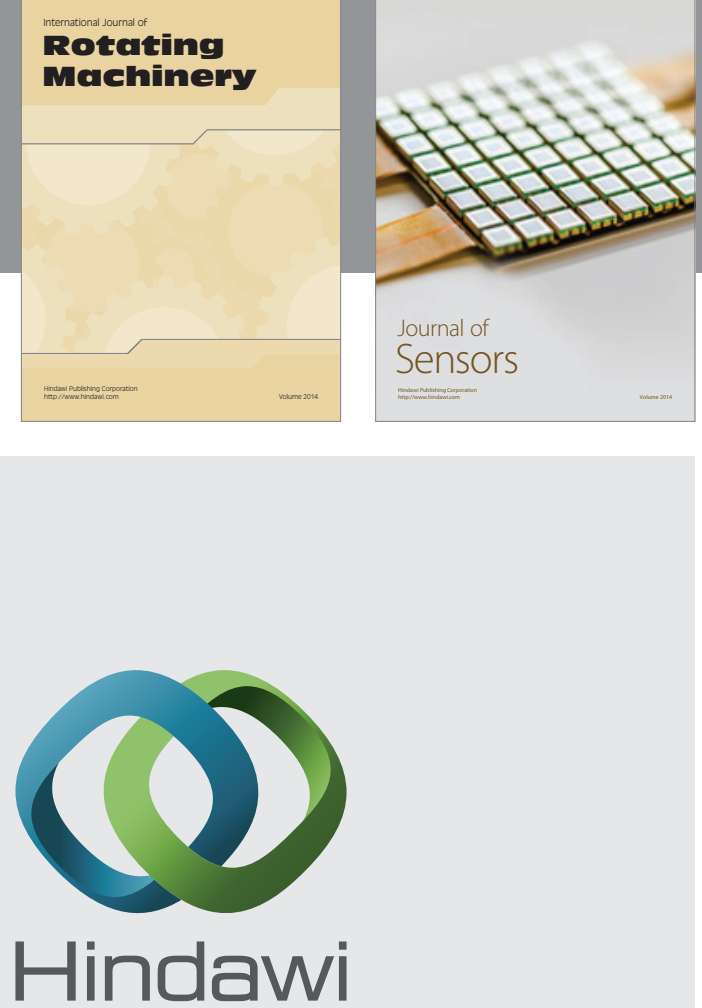

Submit your manuscripts at http://www.hindawi.com
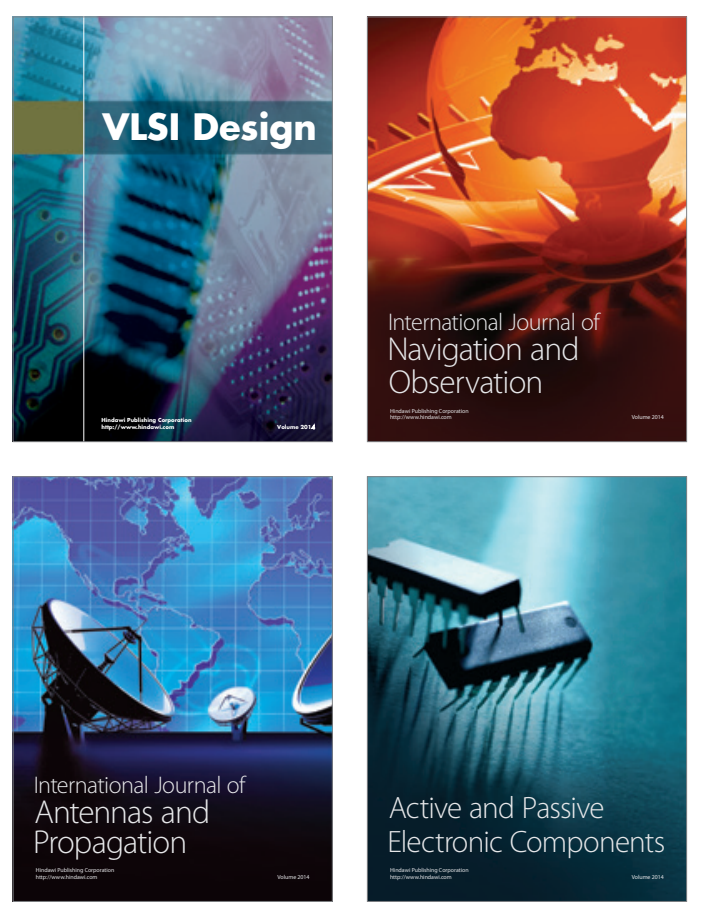
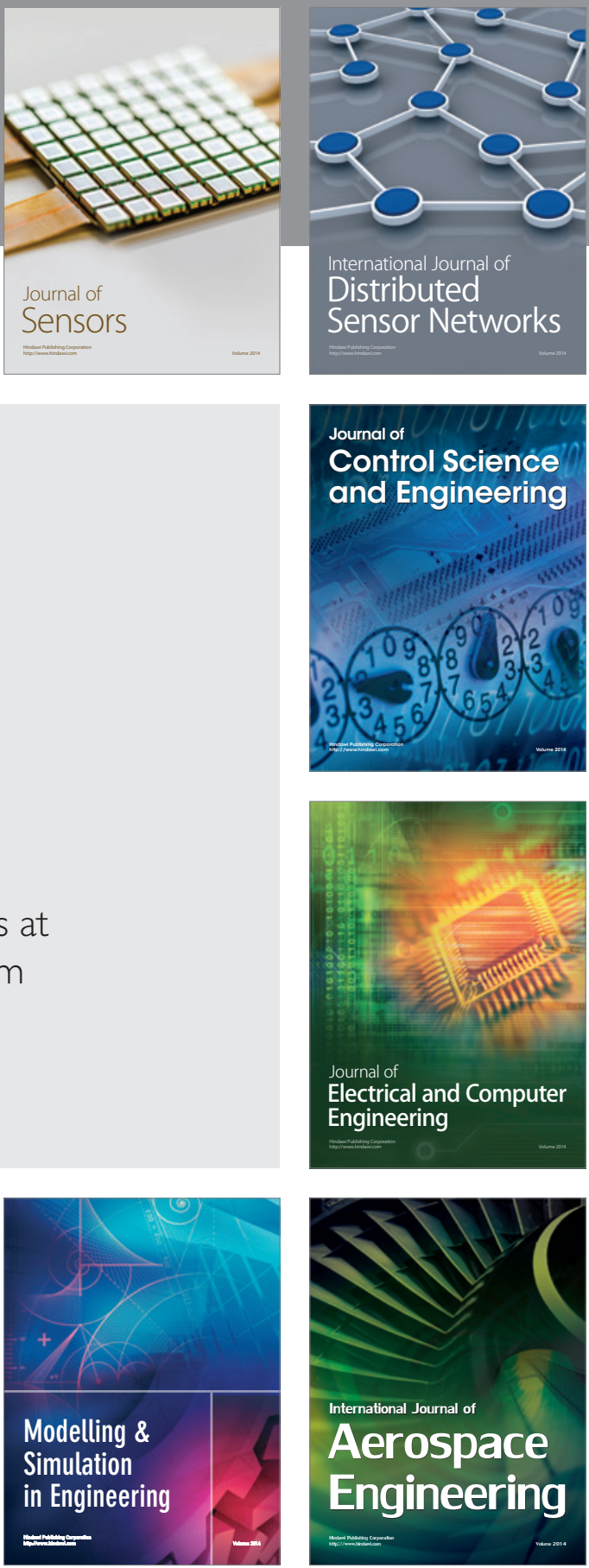

Journal of

Control Science

and Engineering
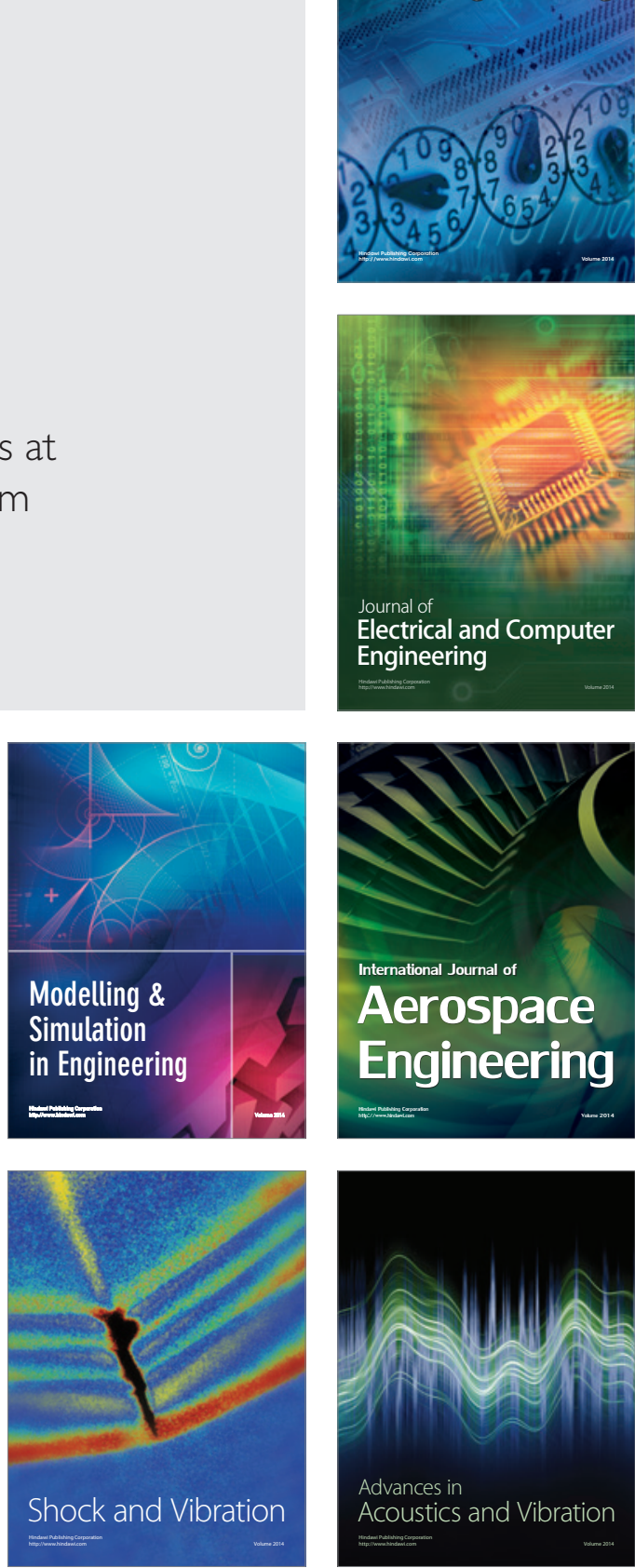